\title{
Research on Decision-making Model of Power Grid Construction Projects Based on Matter Element Extension and Weingartner
}

\author{
Xianing Jin $^{1,}$ a, Zhenyu Xue ${ }^{1, b}$, Yi Song ${ }^{1, c}$, \\ Jing $\mathrm{Xu}^{2, d}$, Lijie Sun ${ }^{3, \mathrm{e}}$ and Yaru Han ${ }^{3, \mathrm{f} *}$ \\ ${ }^{1}$ State Grid Economic and Technological Research Institute CO., LTD, Beijing 102210, China; \\ ${ }^{2}$ State Grid Tianjin Economic Research Institute, Tianjin 300171, China; \\ ${ }^{3}$ School of Economics and Management, North China Electric Power University, Beijing 102206, \\ China

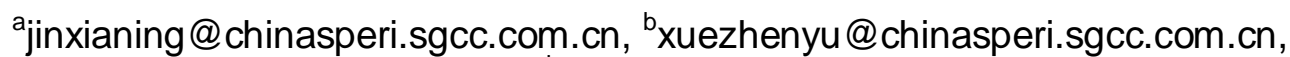 \\ csongyi@chinasperi.sgcc.com.cn, dphoenix_xu@163.com, esunlijie818@163.com, \\ fhfhmth@163.com
} Keywords: Power grid project; Matter element extension; Decision-making model; Decision
optimization

\begin{abstract}
Based on the characteristics of power grid construction projects, in order to meet the development goals of the power grid, firstly, an index system for optimizing the ranking of power grid investment projects is formulated. By establishing an optimization model based on matter element extension for power grid project investment, a batch of projects are initially screened to meet the coordination of power grid operations, the demand of safety and other technical requirements, so as to determine the grid investment reserve projects. Then, on the basis of comprehensive analysis of the development goals of the power grid, the maximum benefit is taken as the objective function, resources and environmental protection goals are converted into constraints, a power grid development aided decision-making model based on Weingartner is established, and methods and strategies for optimizing resource allocation are proposed.
\end{abstract}

\section{Introduction}

With the rapid development of Chinese national economy, power grid companies generally increase their investment in power grids. With the further deepening of the power system reform, the investment environment faced by power grid companies is also more complicated, and at the same time, how to optimize investment efficiency and resources has become a focus that people are increasingly concerned about.

Regarding investment decision-making and project optimization of power grid construction projects, the literature [1] relies on project libraries of different stages and builds decision-making indicators for progressively-advanced power grid construction projects based on the evolution process of grid projects in different levels of project libraries; the literatures [2-5] consider the investment decision-making and optimization problems of power grid construction projects respectively, and put forward corresponding decision-making and optimization measures; the literature [6] proposes a project-based comprehensive project decision-making optimization method, first establish a complete project library, and then optimize the choice of project through two-stage decision-making optimization.

Based on matter element extension and Weingartner, this paper establishes the investment decision-making model for power grid construction projects. First, the reserve project is screened through preliminary evaluation. Then the investment program that can maximize the efficiency of power grid companies is selected by considering the development goals of the power grid and the constraints of investment. 


\section{Establishment of Evaluation Index System for the Optimal Ranking of Power Grid Construction Projects}

In order to ensure that the evaluation system is practicable and the conclusions are scientific and reasonable, the indexes need to follow the principles of systematicness, science, pertinence, operability, and advancement. According to the above principles, comprehensive consideration of all factors affecting the optimal sequencing of grid construction projects, the establishment of an evaluation index system for the optimal ranking of grid construction projects is shown in Fig. 1.

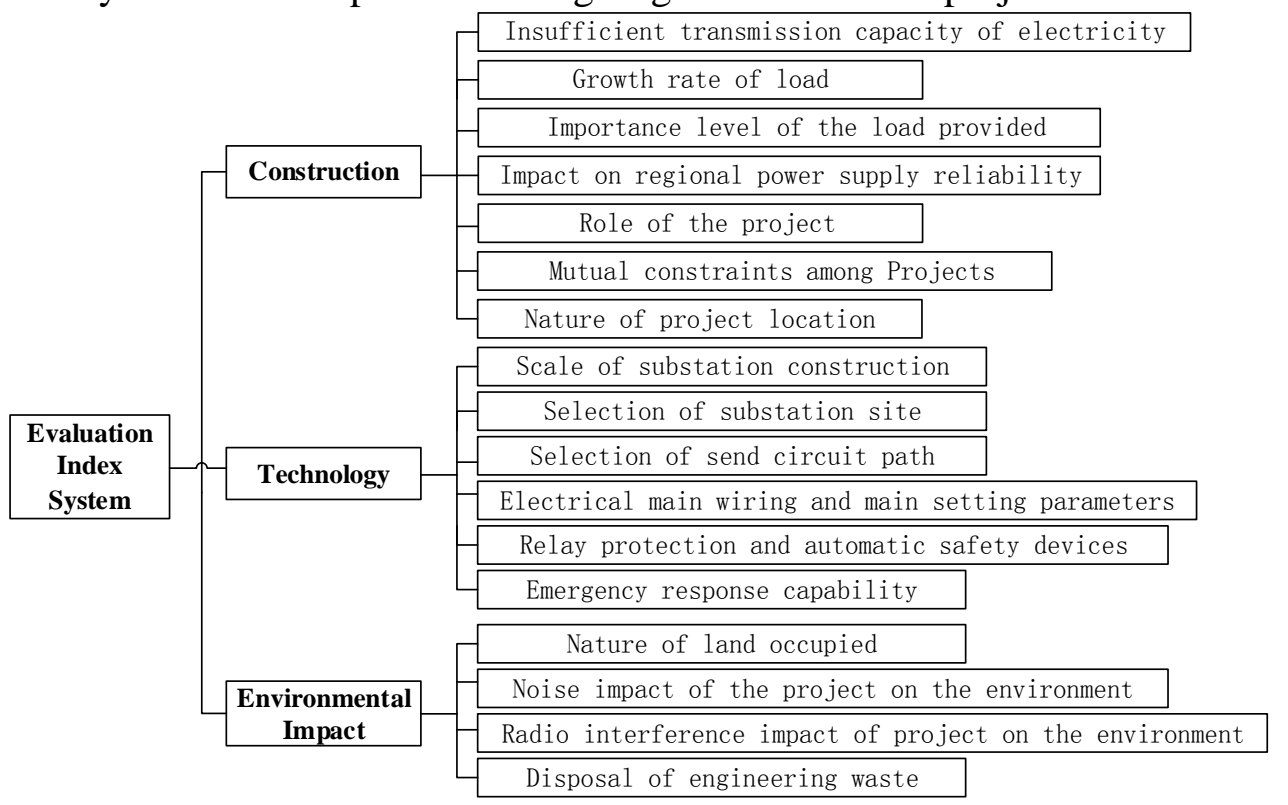

Figure 1 Evaluation indexes for the optimal ranking of grid construction projects

\section{Optimal Ranking Model for Grid Projects Based on Matter Element Extension}

Data Normalization. In this article, taking the example of five power grid construction projects of a city company, the optimization and ranking analysis of the project is performed using the matter element extension model. Qualitative indexes are quantified using the expert rating method, in which the expert scores are all between 0 and 100. The higher the index score, the more priority should be given to investing in the project. At the same time, two quantitative indexes which are insufficient transmission capacity of electricity and the growth rate of load are processed to ensure the consistency of the nature of the data and the range of data values.

Index weight determination. The index weights are determined by subjective weighting methods, that is, expert scoring. The weights of the final indexes are shown in Table 1:

Table 1 Weight of indexes

\begin{tabular}{|c|c|c|c|}
\hline Index & Weight & Index & Weight \\
\hline $\begin{array}{l}\text { Insufficient transmission capacity of } \\
\text { electricity }(\mathrm{C} 1)\end{array}$ & 0.01 & Selection of send circuit path (C10) & 0.05 \\
\hline Growth rate of load ( $\mathrm{C} 2)$ & 0.03 & $\begin{array}{l}\text { Electrical main wiring and main setting } \\
\text { parameters (C11) }\end{array}$ & 0.05 \\
\hline Importance level of the load provided (C3) & 0.07 & $\begin{array}{l}\text { Relay protection and automatic safety } \\
\text { devices (C12) }\end{array}$ & 0.12 \\
\hline $\begin{array}{l}\text { Impact on regional power supply reliability } \\
\text { (C4) }\end{array}$ & 0.05 & Emergency response capability (C13) & 0.08 \\
\hline Role of the project（C5) & 0.11 & Nature of land occupied (C14) & 0.04 \\
\hline Mutual constraints among Projects (C6) & 0.02 & $\begin{array}{l}\text { Noise impact of the project on the } \\
\text { environment }(\mathrm{C} 15)\end{array}$ & 0.06 \\
\hline Nature of project location (C7) & 0.07 & $\begin{array}{l}\text { Radio interference impact of engineering on } \\
\text { the environment }(\mathrm{C} 16)\end{array}$ & 0.06 \\
\hline Substation construction scale (C8) & 0.06 & Disposal of engineering waste $(\mathrm{C} 17)$ & 0.07 \\
\hline Selection of substation site (C9) & 0.05 & & \\
\hline
\end{tabular}


Determine the classic domain matter matrix, the joint domain matter-element matrix and the matter matrix to be evaluated. In this example, each project is regarded as a matter-element to be evaluated, and a comprehensive ranking analysis of the project is performed based on the evaluation result. In this paper, whether the project is worth investment is divided into four levels: excellent, good, medium, and poor, which are represented by Level I, Level II, Level III, and Level IV, respectively, and then the classic domain element matrixes $R_{N 1} 、 R_{N 2} 、 R_{N 3} 、 R_{N 4}$ and the joint domain matter element matrix $R_{P}$ are established. According to the normalized data, establish a to-be-evaluated matter matrix $R_{0}$, as shown below:

$$
\begin{aligned}
& R_{N 1}=\left(\begin{array}{ccc}
N_{1} & C_{1} & (80,100] \\
& C_{2} & (80,100] \\
& \vdots & \vdots \\
& C_{17} & (80,100]
\end{array}\right) R_{N 2}=\left(\begin{array}{ccc}
N_{2} & C_{1} & (70,80] \\
& C_{2} & (70,80] \\
& \vdots & \vdots \\
& C_{17} & (70,80]
\end{array}\right) R_{N 3}=\left(\begin{array}{ccc}
N_{3} & C_{1} & (60,70] \\
& C_{2} & (60,70] \\
\vdots & \vdots \\
& C_{17} & (60,70]
\end{array}\right) R_{N 4}=\left(\begin{array}{ccc}
N_{4} & C_{1} & (0,60] \\
& C_{2} & (0,60] \\
& \vdots & \vdots \\
& C_{17} & (0,60]
\end{array}\right) R_{P}=\left(\begin{array}{ccc}
P & C_{1} & (0,100] \\
& C_{2} & (0,100] \\
\vdots & \vdots \\
& C_{17} & (0,100]
\end{array}\right) \\
& R_{0}=\left(\begin{array}{ccccccc}
P_{0} & C_{1} & 80 & 85 & 90 & 86 & 82 \\
& C_{2} & 77 & 79 & 84 & 80 & 85 \\
& C_{3} & 80 & 83 & 72 & 78 & 76 \\
& C_{4} & 78 & 84 & 85 & 87 & 89 \\
& C_{5} & 82 & 85 & 87 & 80 & 83 \\
& C_{6} & 76 & 76 & 75 & 85 & 81 \\
& C_{7} & 66 & 85 & 80 & 88 & 79 \\
& C_{8} & 76 & 80 & 79 & 79 & 69 \\
& C_{9} & 65 & 78 & 69 & 86 & 84 \\
C_{10} & 83 & 87 & 86 & 89 & 79 \\
C_{11} & 82 & 89 & 88 & 83 & 86 \\
C_{12} & 77 & 69 & 83 & 78 & 78 \\
& C_{13} & 79 & 86 & 80 & 89 & 79 \\
C_{14} & 70 & 68 & 86 & 88 & 83 \\
C_{15} & 87 & 83 & 88 & 85 & 76 \\
C_{16} & 85 & 86 & 79 & 87 & 72 \\
C_{17} & 86 & 88 & 86 & 85 & 80
\end{array}\right)
\end{aligned}
$$

Calculate the correlation degree between each index with each rating level. The correlation degree actually describes the degree of attribution of each index of the object to be evaluated with respect to each evaluation level, and is equivalent to the degree of membership of the fuzzy set described in fuzzy mathematics. Calculate the correlation degree of each item of different projects with respect to four evaluation levels, and the greater the correlation degree, the higher the degree of attribution of the index to the evaluation level.

Analyze the Optimal Ranking of Project. The weighted sum of the correlation degree of each index with respect to each evaluation level is obtained, and the comprehensive correlation degree of each item with respect to each evaluation level is obtained, and the projects are ranked according to the level evaluation results. The results are shown in Table 2:

Table 2 Comprehensive level rating

\begin{tabular}{llllll}
\hline & I & II & III & IV & Rating \\
\hline Project A & 0.0805 & 0.095 & 0.0805 & 0 & II \\
Project B & 0.187 & 0.021 & 0.020 & 0 & I \\
Project C & 0.172 & 0.036 & 0.005 & 0 & I \\
Project D & 0.209 & 0.044 & 0 & 0 & I \\
Project E & 0.0795 & 0.108 & 0.006 & 0 & II \\
\hline
\end{tabular}

From Table 2, we can see that in the five projects of this case, the projects B, C, and D are better, and the three projects that are selected can be ranked: Project D is better than Project B, and Project $\mathrm{B}$ is better than Project $\mathrm{C}$.

\section{Multi-objective optimization of power grid development decision-making model based on Weingartner}

Economic factors are the factors that must be taken into account in power grid construction projects. Since the optimal ranking of power grid construction projects in the early stages did not consider 
economic indexes, this model uses the maximum net present value as the objective function and selects the optimal project under certain constraints [7,8]. The mathematical expression of the model is as follows:

The objective function is the maximum net present value of the selected solution.

$$
\operatorname{Max} \sum_{j=1}^{m} \sum_{t=0}^{n}\left(C I_{j}-C O_{j}\right)\left(1+i_{0}\right) \bullet x_{j}
$$

Where $j$ is the project number, $j=1,2, \cdots, m, x_{j}$ represents decision-making variable,

$$
x_{j}= \begin{cases}0 & \text { reject project } j \\ 1 & \text { accept project } j\end{cases}
$$

Meet the following constraints:

Finance, manpower, material resources and other resource constraints

$$
\sum_{j=1}^{m} C_{j t} x_{j} \leq b_{t} \quad(t=0,1, \cdots, n)
$$

Where $C_{j \mathrm{t}}$ is the amount of resources needed for the project $j$ in year $t ; b_{t}$ is the amount of availability for a resource in year $t$.

Mutually exclusive program constraints

$$
x_{a}+x_{b}+\cdots+x_{k} \leq 1
$$

Where $x_{a}, x_{b}, \cdots, x_{k}$ are the decision variables of mutually exclusive projects $a, b, \cdots, k$ in the $m$ candidate projects .

Dependency constraints

$$
x_{a} \leq x_{b}
$$

In the formula, project $a$ depends on the project $b$. That is, if $b$ is not selected, $a$ can't be selected; if $b$ is selected, a can be considered.

Closely complementary constraints

$$
x_{c}=x_{d}
$$

The projects in the formula are closely complementary projects, that is, neither of them is selected nor is selected.

Non-closely complementary constraints

$$
\left\{\begin{array}{l}
x_{e}+x_{e f} \leq 1 \\
x_{f}+x_{e f} \leq 1
\end{array}\right.
$$

In the above formula, they are non-closely complementary projects.

Inseparability of project projects

$$
x_{j}=0,1
$$

Either project is either selected $\left(x_{j}=1\right)$ or rejected $\left(x_{j}=0\right)$. It is not allowed to take only one part of a complete project and discard the rest. Expression in mathematics is not allowed as a decimal $\left(0<x_{j}<1\right)$.

In the above part, by using the matter element extension model to optimize the ranking of the five existing decision-making projects, the better projects $\mathrm{B}, \mathrm{C}$, and $\mathrm{D}$ have been selected. It is known that these three projects are mutually exclusive. After calculations and analysis, Project D can meet the constraints of finance, manpower, material resources and other resource constraints within the range of risk that the decision-maker can afford, and obtain the greatest investment 
benefits.

\section{Summary}

This paper first introduces the method of optimal ranking of projects, and then establishes a grid project evaluation index system from three aspects of construction, technology, and environmental impact, and initially selects a batch of projects to build a grid construction project library through the matter element extension model. Then, based on the analysis of the development goals of the power grid, a multi-objective optimization decision-making model for power grid development was established by considering various constraints. The case demonstration results show that the investment decision-making model has operability, and the evaluation indexes of grid projects can play an important role in the investment decision-making stage.

\section{Acknowledgments}

This work was one of the results of the science and technology project of State Grid Corporation headquarters called "Research and Application of Equipment Statistical Analysis System and Decision-making Model of Grid Development Based on Real-time Information" (Project No.B3441317K008).

\section{References}

[1] Y.P. Zhu, W. Feng, Multi-level progressive decision index design for grid construction projects, Technology Square. 08 (2017) 59-62. (in Chinese)

[2] H.R. Zhao, H. Wang, Y.H. Han, et al, Research on investment optimization for grid construction projects and aid decision-making systems for grid investment, East China Electric Power. 06(2007) 23-25. (in Chinese)

[3] X.S. Yuan, Y.F. Tang, Optimization Analysis of Investment Decision of Power Grid Construction Projects, Guizhou Electric Power Technology. 16 (2013) 10-12. (in Chinese)

[4] J. Dong, B. Ma, Research on Optimal Portfolio Model of Power Grid Considering Social Benefit, Operational Research and Management. 19 (2010) 131-135. (in Chinese)

[5] L.Y. Kou, J. Wang, J. Liu, Research on investment optimization model for power grid construction projects and implementation strategy, Energy Technology Economy. 24 (2012) 48-52. (in Chinese)

[6] S.Y. Ge, D.X. Xu, H. Liu, et al, Two-Stage Project Integrated Decision Optimization Based on Project Library, Power System Protection and Control. 40 (2012) 118-123+128. (in Chinese)

[7] J. Prina, Investment decision making in a deregulated electric industry using stochastic Dominance, Proceedings of the 2000 IEEE Engineering Management Society (2000). p.546-551.

[8] C. Cambini, A. Meletiou, E. Bompard, et al, Market and regulatory factors influencing smart-grid investment in Europe: evidence from pilot projects and implications for reform, Utilities Policy. (2016) 36-47. 